Article

\title{
Surface Nitridation of Aluminum Nanoparticles by Off-Line Operation and Its Kinetics Analysis
}

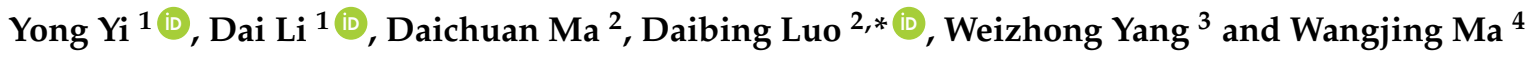 \\ 1 School of Materials Science and Engineering, Southwest University of Science and Technology, \\ Mianyang 621010, China; yiyong@swust.edu.cn (Y.Y.); daili@swust.edu.cn (D.L.) \\ 2 Analytical \& Testing Center, Sichuan University, Chengdu 610064, China; dcma@scu.edu.cn \\ 3 College of Materials Science and Engineering, Sichuan University, Chengdu 610064, China; scuywz@139.com \\ 4 Technical Institute of Physics and Chemistry, Chinese Academy of Sciences, Beijing 100190, China; \\ wjma@mail.ipc.ac.cn \\ * Correspondence: luodb@scu.edu.cn; Tel.: +86-28-8541-2949
}

Received: 15 March 2018; Accepted: 20 April 2018; Published: 23 April 2018

\begin{abstract}
To improve combustion efficiency and anti-oxidation property of aluminum nanoparticles (ANs), surface nitridation of ANs was performed in a pipe furnace under the protection of nitrogen gas in a glove-operation hermetic box via an off-line nitridation process. The product was characterized by transmission electron microscopy (TEM), X-ray diffraction (XRD), and X-ray photoelectron spectroscopy (XPS) analysis. A core-shell nanostructure with an aluminum nitride (AlN) coating on the ANs core was observed. The empirical kinetic triplets $(E a, A$, and $\mathrm{f}(\alpha))$ for the nitridation of ANs, for the first time, were calculated and analyzed using five types of iso-conversional methods and a differentiation method. The effects of the kinetics of the reaction were investigated by simultaneous differential scanning calorimetry-thermogravimetry (DSC-TG) and thermal analysis using linear programmed temperature at different heating rates.
\end{abstract}

Keywords: aluminum nanoparticles; surface nitridation; core-shell structure; kinetic analysis

\section{Introduction}

Aluminum nanoparticles (ANs) are currently widely used in solid propellants, explosives and pyrotechnics because of their high combustion enthalpy and low-temperature oxidation ability. As an excellent propellant, ANs show advantages in combustion applications such as high heat, fast energy releasing rate, burning completeness without cluster aggregation in combustion $[1,2]$. Nowadays, there are various methods to prepare ANs materials mainly including: wire electrical explosive process $[3,4]$, vacuum spray technique [5,6], ball milling $[7,8]$, plasma evaporation [9], inhomogeneous tensile deformation [10,11], and flow-levitation method [12]. Since ANs have a large active surface area and high surface energy, they can be easily oxidized and deactivated in the air, thus, limiting their practical use in propellants. Therefore, it is of high significance to cover inactive layers on ANs as an effective protecting coating to avoid the oxidation of ANs. The popular materials used for ANs coatings include $\mathrm{Ni}$ [13], $\mathrm{C}$ [14], $\mathrm{Fe}_{2} \mathrm{O}_{3}$ [15], $\mathrm{AlB}_{2}$ [16], perfluoroalkyl carboxylic acids [17], polyethylene [18], and other organics [19]. These materials have some limitations in combustion process because they are converted into species without contributions to the energy release. In addition, some coating species are easily oxidized in storage environments and even react with the coated ANs, thus greatly decreasing the combustion efficiency of ANs.

On the other hand, previous research has shown that propellants containing between 42 and $75 \%$ of ANs can achieve a very high burning rate [1]. Therefore, it is an ideal strategy to introduce foreign materials serving as the protective layers as well as the additives into ANs to obtain high efficiency 
in propellent materials. Varieties of species can be used for ANs coatings to improve the combustion efficiency in comparison with the original particles. Aluminum nitride (AlN) materials have excellent stability at low temperature and high resistance to corrosion $[20,21]$. More importantly, AlN does not react with $\mathrm{O}_{2}$ at room temperature while the $\mathrm{AlN}-\mathrm{O}_{2}$ reaction occurs violently at $900{ }^{\circ} \mathrm{C}[22,23]$. In addition, this $\mathrm{AlN}-\mathrm{O}_{2}$ reaction is an exothermic reaction, which is a favorable factor like metal additives in terms of energy contribution. Hence, the limitation of the loss of surface activity may be addressed when ANs are coated with AlN layers.

Successful methods to prepare AlN coatings on ANs with fine nanostructures and without impurity incorporation is still a challenge because many preparation methods involve operations in ambient conditions and are affected by ambient air and temperature. In this paper, we propose a novel method for the surface nitridation of ANs. This method is based on flow-levitation (FL) technology using off-line nitridation operation, which can greatly reduce the ambient turbulence and increase product quality. On the other hand, even though the synthesis of AlN materials are extensively studied, it is still of great importance to analyze the nitridation kinetics, as it gives information on the physicochemical characteristics of the products in the reaction [24,25]. Study on the surface nitridation kinetics helps us to find the effect of reaction conditions (such as heating rate, treatment temperature) on the products. However, the available data for the nitridation kinetics of aluminum powder is relatively poorly reported in the current literature. To our knowledge, no accurate studies have been carried out for the ANs nitridation kinetic parameters to date. In this study, we make a detailed account of the surface nitridation of ANs including off-line operation, elemental analysis, morphology characterization, and the kinetic calculation for the first time. The kinetic triplets of the nitridation process were investigated to set up a general mechanistic model for a wide range of treatment temperature. A possible surface nitridation mechanism for ANs was also suggested. It should be noted that in this research, the off-line nitridation processes and kinetics study using DSC-TG were simultaneously carried out, and the former was guided by the results of the latter.

\section{Experimental Section}

ANs were prepared by FL method according to the standard operational manual. The surface nitridation of ANs was suggested by off-line nitridation method. The phase, surface morphology, and microstructure of the products were characterized by X-ray diffraction (XRD, X Pert PRO, $\mathrm{CuK}_{\alpha}, 40 \mathrm{kV}, 250 \mathrm{~mA}$, Almelo Holland, The Netherlands), transmission electron microscopy (TEM, Libra 200FE, Jena, Germany) with electron energy loss spectroscopy (EELS) analysis, and X-ray photoelectron spectroscopy (XPS, XASM 800, Kratos, Manchester, UK). Relative Intensity Ratio (RIR) method was employed to calculate the mass or volume fractions of the particles, which was used to speculate the thickness of the AlN layer. Differential scanning calorimetry-thermogravimetry (DSC-TG) measurements were carried out by a SDT Q600 (TA Instruments, New Castle, 19720 DE, USA) simultaneous thermal analysis device to examine the weight variation of the ANs in nitrogen flow gas.

FL system for ANs preparation: The FL system includes a dual frequency induction power supply (SPG400K2-20, Shuangping Power Technologies Co., Ltd., Dongguan, China), a powder preparation device, and a water recirculating machine. The power supply generates alternating magnetic field under high voltage, which can make the metal balls melt and suspended at a certain position. The powder preparation device includes the wire-silk system, powder classification system, collecting system, and pipe connection system. The water recirculating the machine supplies cooling water to keep the temperature of the system.

Surface nitridation system for ANs: The nitridation system was customized with an oven and glove box sections combined into one unit (Figure 1). They were separated by the oven lid. The open and close status of the lid could be controlled by foot pedals. The lid was closed when the oven was working. After the heating treatment, the oven and the glove box were connected by opening the lid to have the same atmospheric condition. Four circular holes $(2 \times \Phi 12 \mathrm{~mm}$ and $2 \times \Phi 15 \mathrm{~mm})$ were drilled in the lid, which could introduce the gas required for heating and let the exhaust gas out through 
a backup connector. The whole process was performed in the hermetic glove box filled with nitrogen gas to avoid the oxidation of ANs. The heating rate, temperature holding time, and heating stage could be tuned, and the temperature precision was controlled at $\pm 2{ }^{\circ} \mathrm{C}$. A circular tray for the placement of ANs materials that needed heating was set in the heating zone of the oven. Reagents $\left(\mathrm{CaCl}_{2}, \mathrm{Na}_{2} \mathrm{SO}_{3}\right.$, analytical grade, Sigma-Aldrich, Shanghai, China) to remove $\mathrm{H}_{2} \mathrm{O}$ and $\mathrm{O}_{2}$ were placed in the box, and the $\mathrm{H}_{2} \mathrm{O}$ content was kept below 0.1 ppm while the $\mathrm{O}_{2}$ content was below 1 ppm.

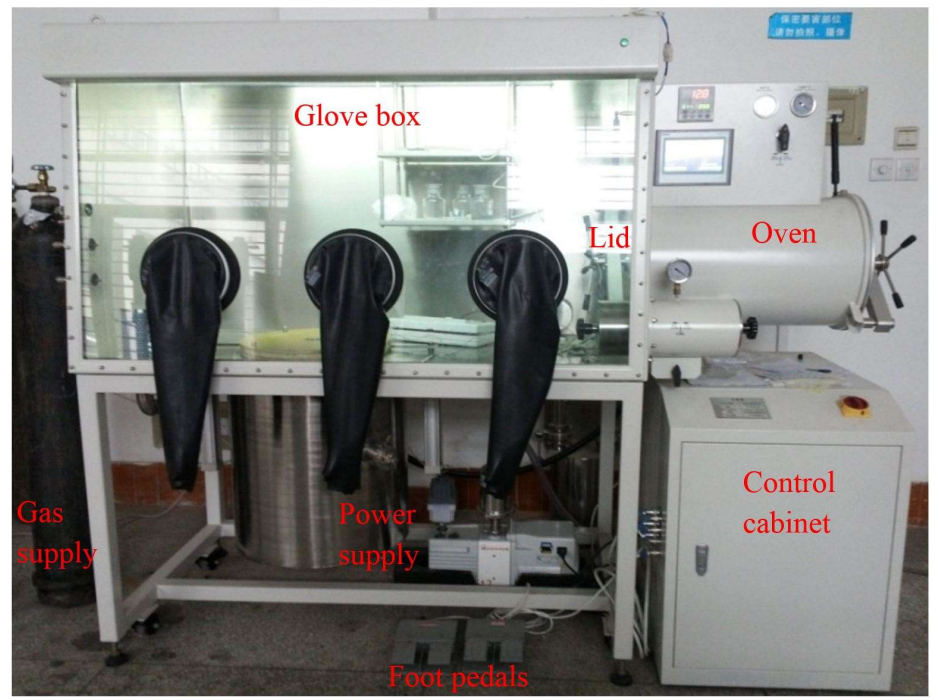

Figure 1. Photograph of the nitridation setup.

Off-line nitridation operation: The treatment parameters were set referenced to the kinetic calculations. When the vacuum degree achieved $-66 \mathrm{KPa}$ by a pump, the atmospheric condition in the oven and the tool transition box was adjusted to the same vacuum. Then the oven lid was promoted to the highest level controlled by the foot plate. A crucible filled with ANs was placed in the center of the circle tray. Then the oven lid was decreased to the lowest position and the heating process was started with respect to the heating program. Each nitridation was performed with a temperature at $550-600{ }^{\circ} \mathrm{C}$ for 30,60 and 90 min under the protection of highly pure $\mathrm{N}_{2}$. Each nitridation at one temperature treatment was carried out at $5,7,8$, and $9{ }^{\circ} \mathrm{C} \cdot \mathrm{min}^{-1}$ heating rate 3 times. The nitridation samples were characterized by XRD, XPS and DSC-TG. AlN coatings were thus formed on the nanoparticle surface through the following reaction (1).

$$
2 \mathrm{Al}(\mathrm{s})+\mathrm{N}_{2}(\mathrm{~g}) \rightarrow 2 \mathrm{AlN}(\mathrm{s})
$$

\section{Results and Discussion}

\subsection{Structural and Elemental Analysis}

\subsubsection{Transmission Electron Microscopy (TEM)}

FL technology is one of the gas-phased methods for the preparation of nanomaterials, which can produce ANs in mass production and allows the in-situ coating process. The particle shape was characterized by TEM. Figure 2a shows a TEM image of the ANs after nitridation treatment at $550{ }^{\circ} \mathrm{C}$. Spherical particles can be clearly observed. A single nanoparticle with well circle shape is shown in Figure 2b. After the surface nitridation process, the generated nanoparticles showed a core-shell structure with a shell thickness of 6-7 nm (scaled by the arrows). This nanostructure is favorable for the prevention of self-ignition and increasing the anti-oxidation property. Typical morphology and elemental distribution are illustrated in Figure 2c. Al (red), N (green), and O (blue) elements are 
found by line scan in the microstructure denoted in a different color, suggesting $\mathrm{N}$ element has been successfully introduced into the ANs. The elemental analysis from TEM is useful in vision observation as supplementary information in relationship with other characterization, even though the quantitative level is not high.
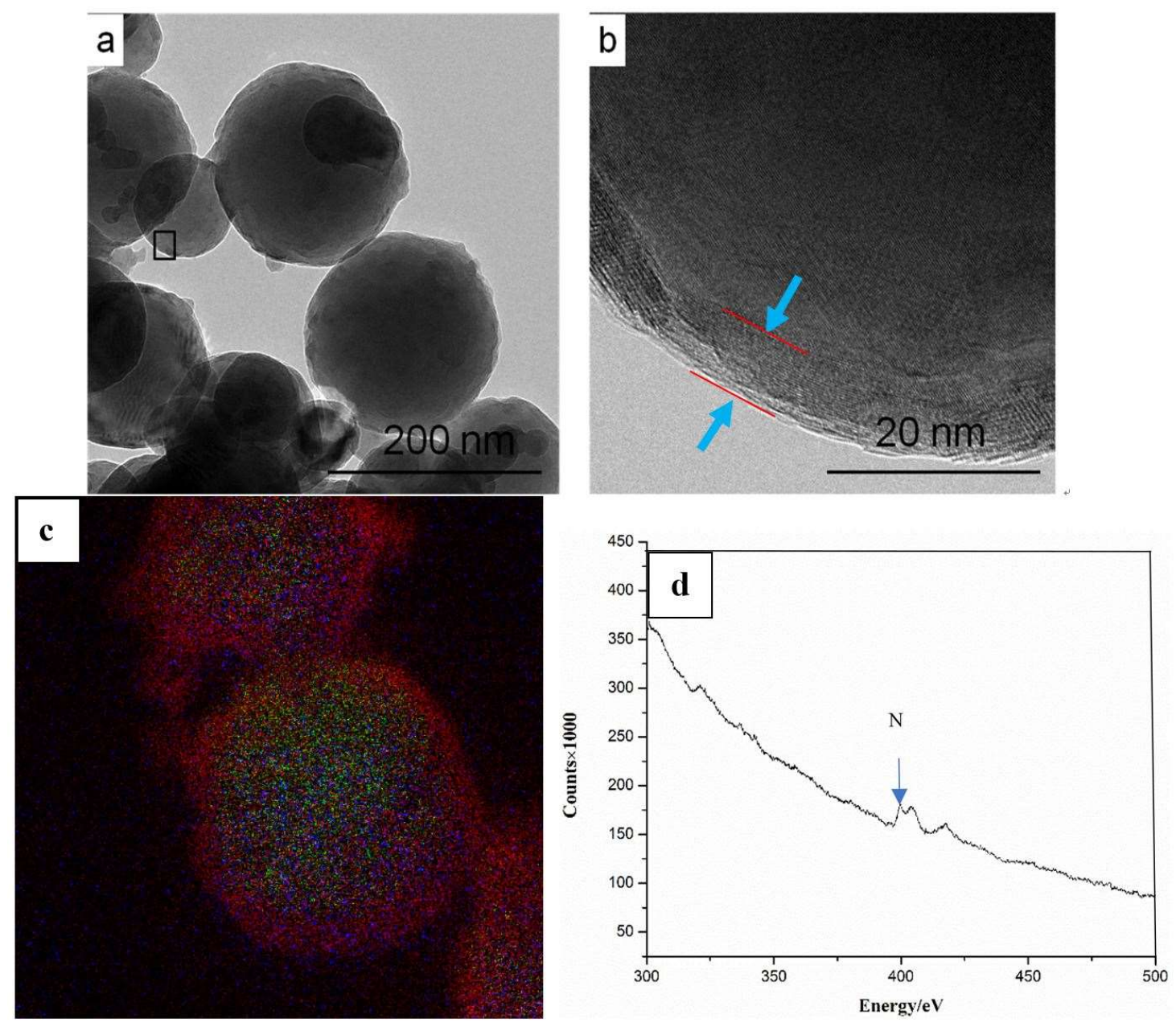

Figure 2. (a) Transmission electron microscopy (TEM) image of the aluminum nanoparticles (ANs) after surface nitridation at $550{ }^{\circ} \mathrm{C}$; (b) TEM with higher resolution for segmental magnification, and (c) Surface elemental distribution with color indication: Al (red), N (green), and O (blue). Noting that a slight color aberration may be observed on a nanosphere structure due to the difference of trap depth energy of the TEM detection; (d) A peak at $401 \mathrm{eV}$ characteristic of nitrogen.

EELS was further used for the elemental identification on the nanoparticles. A peak at $401 \mathrm{eV}$ characteristic of nitrogen is clearly observed in Figure $2 d$, which confirms that AlN coating was successfully formed on the nanoparticle surface. This composite product with a core-shell structure was generated mainly due to the high reactivity and large surface area of ANs. The mass fractions of AlN calculated by RIR are 40.3\%, 40.6\%, and 41\% for the temperature holding time at 30, 60, and 90 min, respectively at the nitridation temperature of $550{ }^{\circ} \mathrm{C}$. The variation of these mass fractions was less than $1 \%$, indicating the formed AlN layer with certain thickness hinders the further nitridation reaction after the temperature holding time is longer than a certain period (i.e., $30 \mathrm{~min}$ for this sample). In summary, AlN coatings can effectively prevent the nanoparticles from deep nitridation and most likely from oxidization reaction. 


\subsubsection{X-ray Diffraction (XRD)}

Temperature effect on the nitridation process was studied by XRD analysis. The XRD results of the surface nitridation experiments carried out at $560^{\circ} \mathrm{C}, 570{ }^{\circ} \mathrm{C}, 580{ }^{\circ} \mathrm{C}$, and $600^{\circ} \mathrm{C}$ with a thermal-insulation time of $30 \mathrm{~min}$ are compared in Figure 3. The appearance of AlN peaks at $45.862^{\circ}$ and $67.032^{\circ}$ at $2 \theta$ is observed, which are identified as the (400) and (440) facets of AlN with a hexagonal lattice. The diffraction peaks at $38.4^{\circ}, 44.6^{\circ}, 64.9^{\circ}, 78.0^{\circ}$, and $82.2^{\circ}$ are classified to the (111), (200), (220), (311), and (222) facets, respectively, of aluminum.

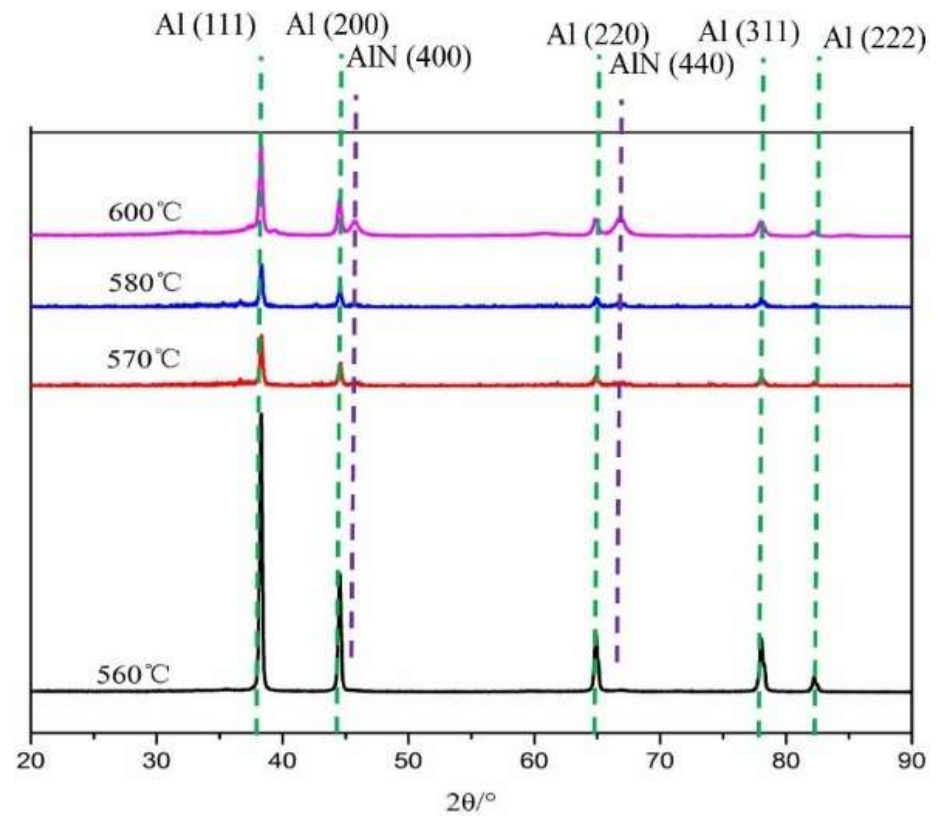

Figure 3. X-ray diffraction (XRD) patterns of the aluminum nanoparticles (ANs) after surface nitridation at different treatment temperature from bottom to top (black: $560{ }^{\circ} \mathrm{C}$ ), (red: $570{ }^{\circ} \mathrm{C}$ ), (blue: $580{ }^{\circ} \mathrm{C}$ ), and (rose: $600^{\circ} \mathrm{C}$ ) respectively.

The stability or resistance to oxidation property of the sample treated at $\left(600^{\circ} \mathrm{C}\right)$ was estimated by XRD characterization after the nanoparticles with AIN coatings were placed in fresh air (room temperature $25^{\circ} \mathrm{C}$ ) for $1 \mathrm{~h}$. There were almost no changes in the XRD curves since neither new peaks appeared nor old peaks disappeared, which indicate the AlN coatings could prevent the coated metal cores from oxidation in the air with a stable nanostructure (Supplementary Materials: Figure S1).

\subsubsection{X-ray Photoelectron Spectroscopy (XPS)}

The elemental composition of the nanoparticle surface was studied by XPS, and the results are shown in Figure 4. The peak between $394 \mathrm{eV}$ and $398 \mathrm{eV}$ in Figure $4 \mathrm{~b}$ indicates the presence of nitrogen. The XPS measurements confirm that AIN coatings were successfully formed on the ANs. The peaks due to the presence of oxygen are found in the $527.5-535 \mathrm{eV}$ region demonstrating the presence of $\mathrm{Al}_{2} \mathrm{O}_{3}$ as a consequence of the chemical reaction between aluminum and oxygen (Figure $4 \mathrm{c}$ ). A decrease of $\mathrm{Al}_{2} \mathrm{O}_{3}$ content with the increasing of temperature is observed due to the reaction (2).

$$
\mathrm{Al}_{2} \mathrm{O}_{3}+4 \mathrm{Al} \rightarrow 3 \mathrm{Al}_{2} \mathrm{O}
$$

It takes place at $500-600{ }^{\circ} \mathrm{C}$ where the $\mathrm{Al}_{2} \mathrm{O}$ is a kind of volatile species easily removed [26]. It was found that the oxidation of ANs takes places very easily in the storage environments [1]. The nitridation treatment at high temperature allows the ANs to lower the oxygen content in comparison with samples treated at low temperature. 

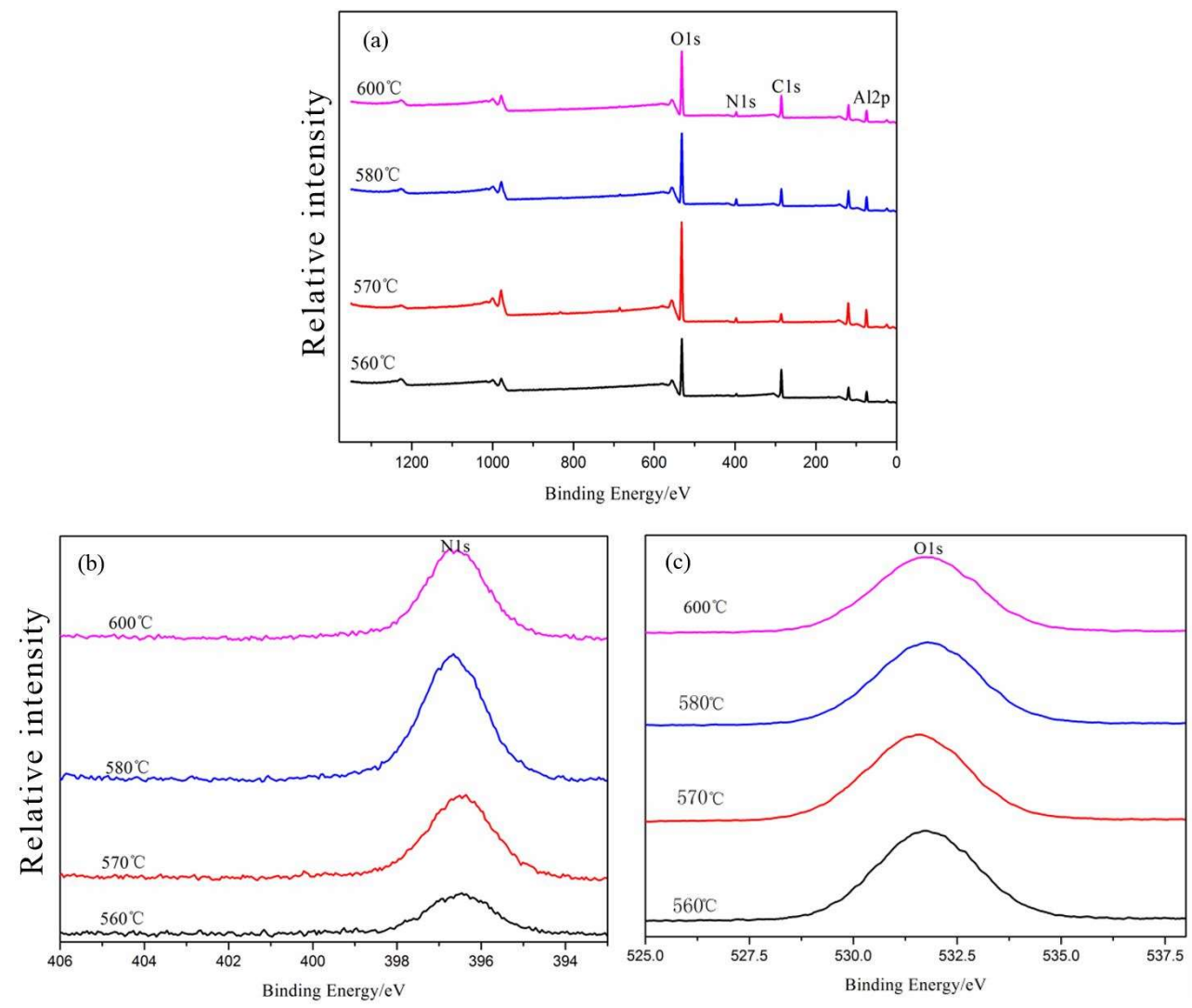

Figure 4. (a) X-ray photoelectron spectroscopy (XPS) of the ANs after surface nitridation, and higher resolution recording at (b) 393-406 eV for $\mathrm{N}$ observation and (c) 525-538 eV region for O observation.

\subsection{Differential Scanning Calorimetry—Thermogravimetry (DSC-TG) Analysis}

\subsubsection{Study Conducted between 25 and $700{ }^{\circ} \mathrm{C}$ at Different Heating Rates}

The typical DSC-TG and DSC curves under $\mathrm{N}_{2}$ flow $\left(50 \mathrm{~mL} \cdot \mathrm{min}^{-1}\right)$ at different heating rates $\left(5,7,8\right.$, and $\left.9{ }^{\circ} \mathrm{C} \cdot \mathrm{min}^{-1}\right)$ are shown in Figure 5. The mass loss from the samples below $200{ }^{\circ} \mathrm{C}$ is mainly caused by the desorption of gaseous species and water vapor and other airborne species adsorbed on the ANs surface. As observed from Figure 5b, each DSC curve has an exothermic peak (for nitridation reaction) and an endothermic peak (for sample melting). There are three stages of mass gains (nitrogen introduction) along with the temperature increasing process, and the first stage of the nitridation rate is almost negligible.
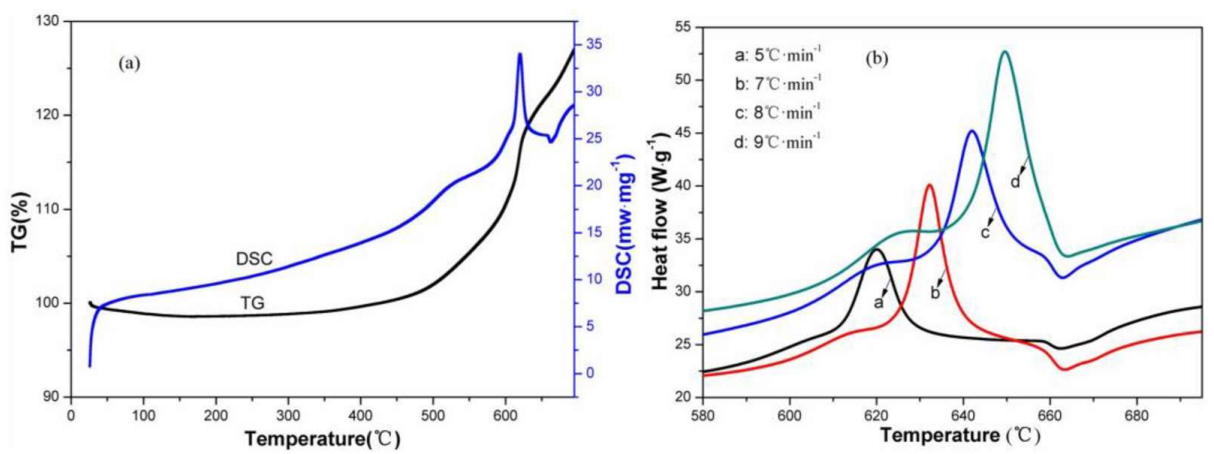

Figure 5. (a) DSC-TG curves with a heating rate at $5^{\circ} \mathrm{C} \cdot \mathrm{min}^{-1} ;(\mathbf{b})$ DSC curves at different heating rates $\left(5,7,8,9^{\circ} \mathrm{C} \cdot \mathrm{min}^{-1}\right)$. 


\subsubsection{Study Conducted between 25 and $1300{ }^{\circ} \mathrm{C}$}

The effect of temperature increase rate on the nitridation of ANs was carried out by the DSC-TG measurements up to $1300{ }^{\circ} \mathrm{C}$ as shown in Figure 6. Each DSC-TG curve could be divided into several regions (Figure 6a), which means that the surface nitridation of the ANs took place through several thermal stages [1]. An endothermic peak at around $660^{\circ} \mathrm{C}$ is caused by the melting of the ANs at a heating rate of $5{ }^{\circ} \mathrm{C} \cdot \mathrm{min}^{-1}$. It can be noted that another exothermic peak at $731{ }^{\circ} \mathrm{C}$ is due to the reaction of the remained ANs in the liquid phase with nitrogen. From the TG curves in Figure $6 \mathrm{~b}$, a weight loss process was observed from room temperature to $300^{\circ} \mathrm{C}$, which is due to the evolution of the absorbed $\mathrm{H}_{2} \mathrm{O}$ and other gaseous species on the nanoparticle surface. A sharp increase in the weight gain about $3 \%$ is observed in the $300-600{ }^{\circ} \mathrm{C}$ region. This is related to the introduction of nitrogen element in the heterogeneous reaction between $\mathrm{N}_{2}$ and the ANs. In the $600-638{ }^{\circ} \mathrm{C}$ range, an obvious increase of the weight (about $21 \%$ ) can be observed, since the nitridation reaction occurs intensively. Then, around $4 \%$ increase of the weight is obtained in the $638 \sim 650{ }^{\circ} \mathrm{C}$ region, and the total weight gain was about $50 \%$ in the whole process, while the maximum value of the total weight gain of the ANs in nitridation is $51.85 \%$ referenced to the theoretical calculation. In comparison, the weight gains at 10 and $20{ }^{\circ} \mathrm{C} \cdot \mathrm{min}^{-1}$ were less than that at $5^{\circ} \mathrm{C} \cdot \mathrm{min}^{-1}$ from the TG measurement.
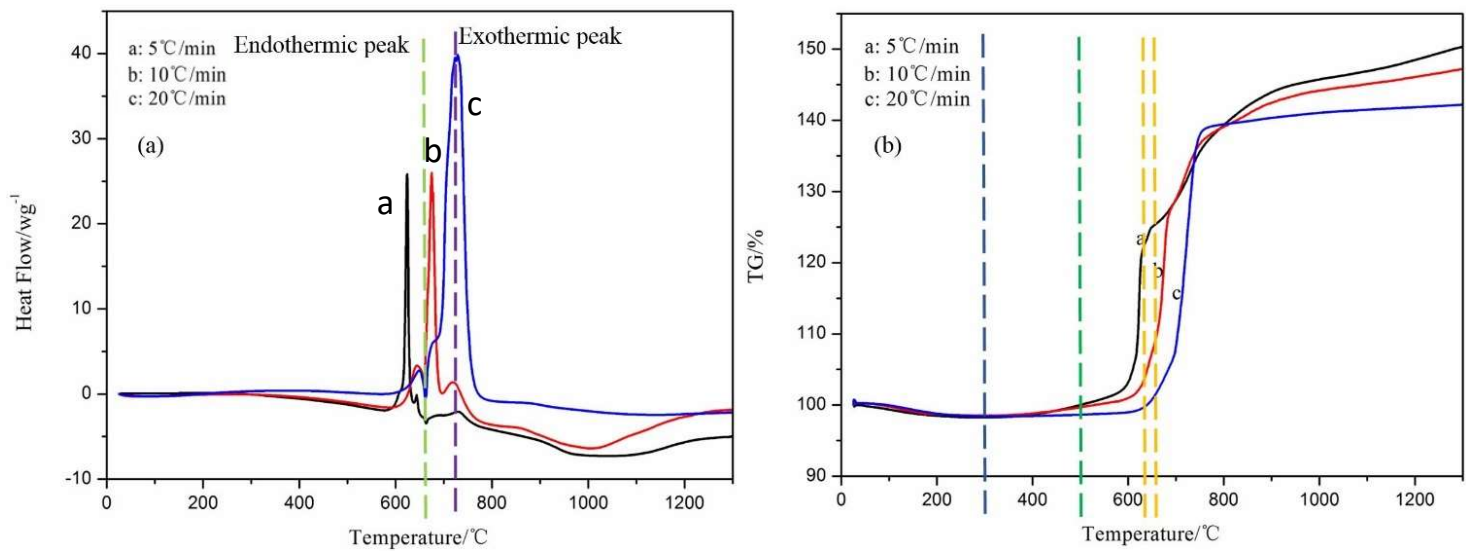

Figure 6. Differential scanning calorimetry-thermogravimetry (DSC-TG) curves for aluminum nanoparticles at different heating rates (i.e., 5, 10, $20^{\circ} \mathrm{C} \cdot \mathrm{min}^{-1}$ ). (a) Differential scanning calorimetry (DSC), (b) Thermogravimetry (TG) curves. The peak characterization and thermal stages are marked with dot line with different colors.

\subsection{Non-Isothermal Reaction Kinetics}

The non-isothermal reaction kinetics can be obtained via the TG curves. The results showed that the temperature ranging from $600-650{ }^{\circ} \mathrm{C}$ was the main stage that was responsible for the surface nitridation process. In order to obtain the kinetic triplets (apparent activation energy $(E a)$, the pre-exponential constant $(A)$ and the most probable kinetic model function $(\mathrm{f}(\alpha))$, DSC measurements with heating rates at $5,7,8$ and $9 \mathrm{~K} \cdot \mathrm{min}^{-1}$ were performed by five integral methods (Ordinary-Integral, MacCallum-Tanner, Satava-Setak, Agrawal, and Flynn-Wall-Ozawa) and one differential method (Kissinger). The dependence of $E a$ on $\alpha$ is an important factor, which should be studied by iso-convension methods in the first stage [27]. Table 1 presents the analysis methods for the kinetics calculation. The $E a$ and $A$ values of the reaction could be obtained by the calculation based on the kinetic equation in differential form:

$$
\mathrm{d} \alpha / \mathrm{d} t=A \cdot \mathrm{f}(\alpha) \mathrm{e}^{-E a /(R T)}
$$


The fractional reaction $(\alpha)$ can be determined from TG measurements by the following equation:

$$
\alpha=\left(m_{\mathrm{t}}-m_{\mathrm{i}}\right) /\left(m_{\mathrm{f}}-m_{\mathrm{i}}\right)
$$

Herein, $m_{\mathrm{t}}, m_{\mathrm{f}}$, and $m_{\mathrm{i}}$ are the initial, final and current sample mass, respectively. The data needed for the Ea calculations were accumulated from the DSC curves and are summarized in Table S1 (See the Supplementary Materials).

Table 1. Kinetic analysis methods.

\begin{tabular}{ccc}
\hline Method & Equation \\
\hline Ordinary-Integral & $\ln \left[G(\alpha) / T^{2}\right]=\ln [(A R / \beta)(1-2 R T / E)]-E / R T$ \\
MacCallum-Tanner & $\lg [G(\alpha)]=\lg [(A E / \beta R)]-0.4828 E^{0.4357}-(0.449+0.217 E) /(0.001 T)$ \\
Satava-Setak & $\lg [G(\alpha)]=\lg (A E / \beta R)-2.315-0.4567 E / R T$ \\
Agrawal & $\ln \left[G(\alpha) / T^{2}\right]=\ln \left\{(A R / \beta E)[1-2(R T / E)] /\left[1-5(R T / E)^{2}\right]\right\}-E / R T$ \\
Flynn-Wall-Ozawa & $\lg \beta=\lg \{A E /[R G(\alpha)]\}-2.315-0.4567 E / R T$ \\
Kissinger & $\ln \left(\beta_{i} / T_{\mathrm{p} i}^{2}\right)=\ln (A R / E)-E / R T_{\mathrm{p} i}, i=1,2,3,4$ \\
\hline
\end{tabular}

Parameters: $\alpha$ : transformation efficiency; $T$ : temperature at time $t ; R$ : gas constant; $A$ : pre-exponential factor; $E(E a)$ : apparent activation energy; $\beta$ : heating rate; $\mathrm{G}(\alpha)$ : integral model function; $T_{\mathrm{p}}$ : peak temperature in the DSC curve.

The dependence of $E a$ on $\alpha$ for the non-isothermal nitridation of the ANs is evaluated using the mentioned methods. Taking a typical example, the $E a$ values were obtained using the Flynn-Wall-Ozawa (F-W-O) method with $\alpha$ values of $0.1-0.9$ and the $\lg \beta-T^{-1}\left(\lg =\log _{10}\right)$ and $E a-\alpha$ relationships are shown in Figure 7 . The $E a$ value of the reaction process changes dramatically as $\alpha$ increases, except in the range of $\alpha=0.1-0.7$, which is almost constant. It is, therefore, feasible to study the reaction mechanism and kinetics over this range. The $T-\alpha$ dependence is introduced into the following equation:

$$
\lg \beta=\lg [A E / R G(\alpha)]-2.315-0.4567 E / R T
$$

and the fitting result is indicated in Figure $7 \mathrm{a}$ as setting the temperature reciprocal $\left(K^{-1}\right)$ as the horizontal coordinate and the logarithm of the temperature increasing rate $(\lg \beta)$ as the $Y$-axis. The $K$ value of -6.525855 is obtained from the slope value of the fitting result with a linearly dependent coefficient $(R)$ as -0.9994 . In this case, the average $E a$ value is calculated as $118.8 \mathrm{~kJ} \cdot \mathrm{mol}^{-1}$ according to $-0.4567 E / R T=-6.525855$. The dependence of $E a$ on $\alpha$ is indicated in Figure $7 \mathrm{~b}$.
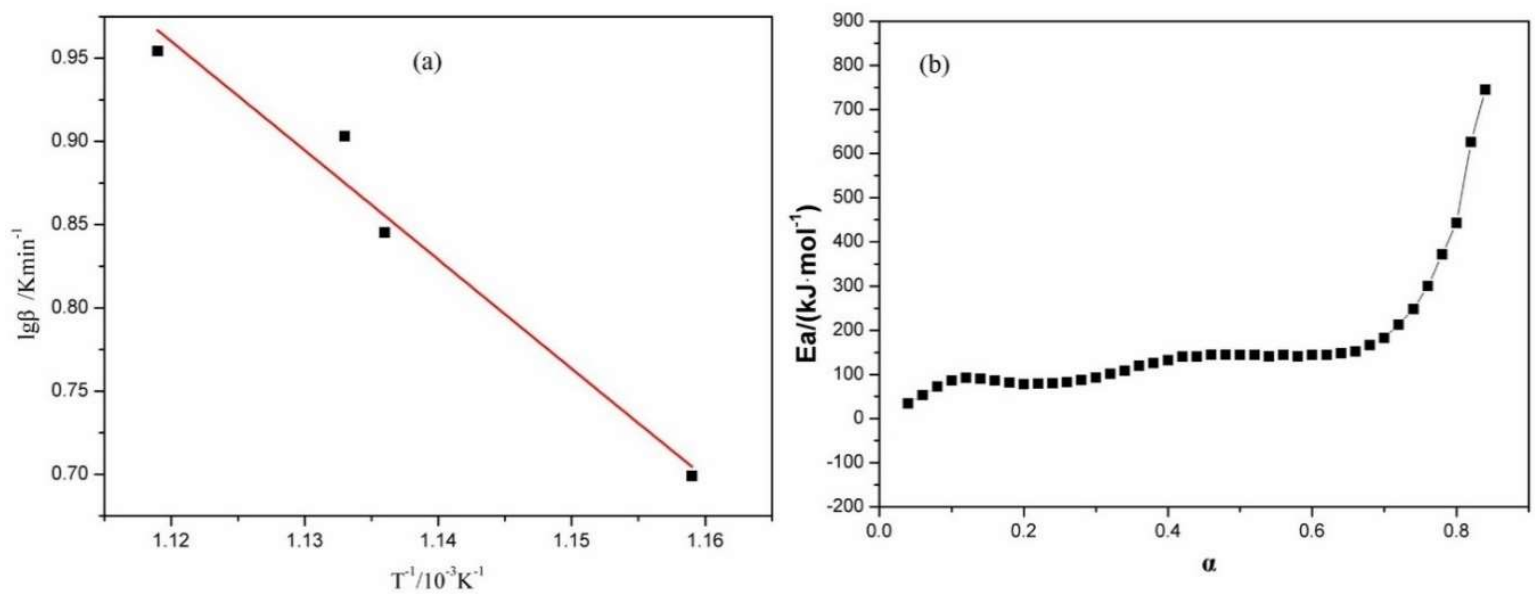

Figure 7. (a) Scatter plots and linear regression curves of $\lg \beta-T^{-1}$; (b) $E a-\alpha$ curve obtained by the F-W-O method with $R=-0.9994$. 
Kissinger method [28], as one differential method, was used for the Ea value calculation. The linear fitting result using Equation (4) with $R$ as -0.9998 and $K$ as -13.11429 is indicated in Figure 8.

$$
\ln \left(\beta_{i} / T_{\mathrm{p} i}^{2}\right)=\ln (A R / E)-E / R T_{\mathrm{p} i}, i=1,2,3,4
$$

The plot obtained by $\ln \left(\beta_{\mathrm{i}} / T_{\mathrm{p} i}{ }^{2}\right)$ versus $1 / T_{\mathrm{p} i}$ could give the $E a$ value as the slope and the $A$ value as the intercept. Then $E a=13.11429 \times 8.314=109.03 \mathrm{~kJ} \cdot \mathrm{mol}^{-1}$ can be directly obtained by $-E / R T=-13.11429$.

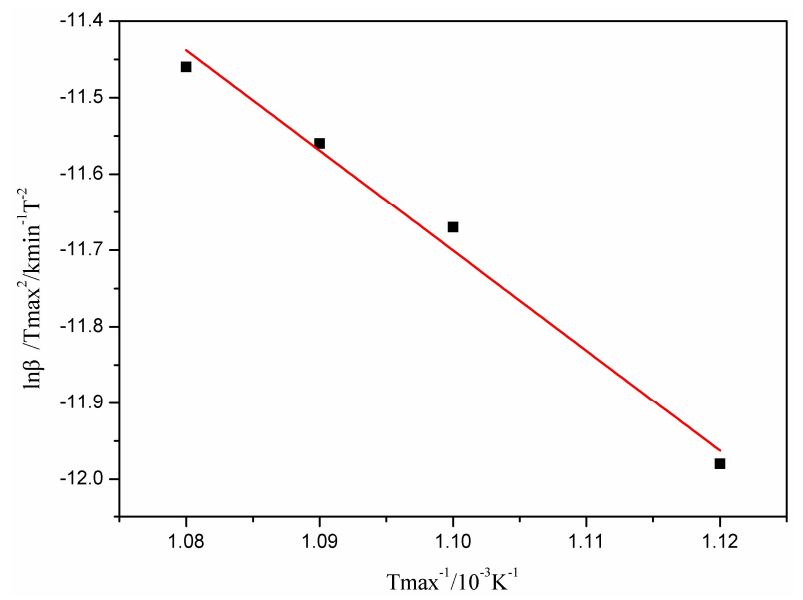

Figure 8. Scatter plots and linear regression curves of $1 / T_{\max }-\ln \beta / T_{\max }{ }^{2}$.

The Ea values calculation by other integral methods (Kissinger, Agrawal, Ordinary-Integral, MacCallum-Tanner, and Satava-Setak) were also performed and the results are summarized in the supplementary information. Forty-one kinds of mechanism functions [28] describing the single non-isothermal DSC curves and the $T-\alpha$ data in Table S1 (Supplementary Materials) were introduced and tested in the equations in Table 1 , and the values of the $E a, \lg A, r$ (linearly dependent coefficient), and $Q$ (square error) were obtained by the least square method at different heating rates $(5,7,8$, and $\left.9{ }^{\circ} \mathrm{C} \cdot \mathrm{min}^{-1}\right)$. The calculated kinetic parameters by different methods are listed in Table 2 with further details. The obtained data suggest that the possible kinetic mechanism of the ANs nitridation process could be determined by the Mampel Power Law with $n=3 / 2$, according to the principle of the multiple scanning method (Kissinger) and the iso-conversion method [29]. The relative integral equation is

$$
\mathrm{G}(\alpha)=\alpha^{3 / 2}
$$

with the corresponding differentiation equation given by (Equation (6))

$$
f(\alpha)=\frac{2}{3} \alpha^{-1 / 2}
$$

Since the reaction mechanism obeys Mampel Power law with $n=3 / 2$, the kinetic equation can be expressed as

$$
\frac{d \alpha}{d t}=10^{3.28} \cdot \alpha^{-1 / 2} \cdot e^{-13439.9 / \mathrm{T}}
$$

Non-isothermal nitridation, instead of isothermal nitridation could be used to determine the activation energy [24]. The combustion properties, such as stability, reactivity, and ignition delay of ANs are greatly changed in comparison with the original ANs [30]. This coating method does not require additional purification treatments. Furthermore, this technique of surface coating by nitrogen protection before they interact with air, could effectively improve the reaction rate. Through this unique study, the mechanism for the surface nitridation of ANs will be deeply disclosed. In this research, the nitridation parameters (such as heating rate, treatment temperature, power and gas 
supplies) were properly set according to the kinetic study. A summary of the kinetic study shows that (1) the heating rate $\beta$ may be more reasonable when it was set at $5-9{ }^{\circ} \mathrm{C} \cdot \mathrm{min}^{-1}$; (2) A favorable initial reaction temperature $\left(T_{0}\right)$ should be quickly reached in the nitridation operation; (3) The nitridation temperature $T$ plays an important role in the generated AlN thickness.

Temperature, treatment time, and additives are key factors for the surface nitridation in the off-line operation. The ANs normally have an aluminum oxide coating at $10^{-3} \mu \mathrm{m}$ scale [24] that could be greatly removed from the nitridation process. The heat releasing efficiency of the product in the oxidation process may be higher than that associated with regular Al nanoparticles, thus, promoting the heat flux to the propellant materials.

Table 2. Kinetic parameters of the surface nitridation of ANs.

\begin{tabular}{|c|c|c|c|c|c|}
\hline Method & $\beta /\left({ }^{\circ} \mathrm{C} \cdot \mathrm{mol}^{-1}\right)$ & $\mathrm{E}_{\mathrm{a}} /\left(\mathrm{kJ} \cdot \mathrm{mol}^{-1}\right)$ & $\lg \left(\mathrm{A} \cdot \mathrm{S}^{-1}\right)$ & $\mathbf{r}$ & Q \\
\hline \multirow{4}{*}{ Ordinary-Integral } & 5 & 102.18 & 2.71 & 0.9976 & 0.1220 \\
\hline & 7 & 117.59 & 3.71 & 0.9981 & 0.3198 \\
\hline & 8 & 102.27 & 2.78 & 0.9975 & 0.1981 \\
\hline & 9 & 117.62 & 3.69 & 0.9981 & 0.4535 \\
\hline \multirow{4}{*}{ MacCallum-Tanner } & 5 & 103.29 & 2.88 & 0.9962 & 0.0237 \\
\hline & 7 & 115.61 & 3.96 & 0.9960 & 0.0615 \\
\hline & 8 & 103.06 & 2.90 & 0.9961 & 0.0385 \\
\hline & 9 & 114.68 & 3.61 & 0.9967 & 0.0594 \\
\hline \multirow{4}{*}{ Satava-Sestak } & 5 & 110.40 & 3.54 & 0.9976 & 0.0134 \\
\hline & 7 & 125.28 & 4.43 & 0.9981 & 0.0241 \\
\hline & 8 & 110.71 & 3.86 & 0.9975 & 0.0202 \\
\hline & 9 & 125.48 & 4.42 & 0.9981 & 0.0873 \\
\hline \multirow{4}{*}{ Agrawal } & 5 & 102.18 & 2.71 & 0.9976 & 0.1220 \\
\hline & 7 & 117.59 & 3.71 & 0.9981 & 0.3198 \\
\hline & 8 & 102.27 & 2.78 & 0.9975 & 0.1981 \\
\hline & 9 & 117.62 & 3.69 & 0.9981 & 0.4535 \\
\hline Mean & - & 111.74 & 3.46 & - & - \\
\hline Flynn-Wall-Ozawa & - & 118.8 & - & 0.9994 & - \\
\hline Kissinger & - & 109.03 & 5.2 & 0.9998 & - \\
\hline
\end{tabular}

\section{Conclusions}

Surface nitridation of ANs was successfully performed by an off-line operation protected by nitrogen gas in a sealed system. A core-shell nanostructure was obtained with an AlN shell of 6-7 nm width. The size and shape of the nitridated nanoparticles are almost as same as the original ones. A correlation of the treatment temperature on the elemental contents of the coating process was observed. The effect of the heating rate on the nitridation was estimated. Thermal and TGA analysis have been performed to investigate the surface nitridation process. A rapid weight gain of ANs in nitrogen gas was found in $600-638^{\circ} \mathrm{C}$ range identified as the main stage for the nitridation process. The ANs showed higher weight gain at higher temperatures. Non-isothermal nitridation analysis was carried out at different heating rates under nitrogen protection. The Ea value was obtained through the DSC-TG measurements and calculated using 5 types of integral methods and a differentiation method. The kinetic triplets calculated depending on the DSC-TG data indicated that kinetic mechanism obeys the Mampel Power Law where the nucleation is the rate-determining step. The generated AlN coatings could prevent metal oxidation and increase the combustion efficiency in propellants and prolong the working life of the enclosed metal cores.

Supplementary Materials: The following are available online at http:/ /www.mdpi.com/2075-4701/8/4/289/s1, Figure S1: XRD of the nitridation-treatment sample $\left(600^{\circ} \mathrm{C}\right)$ after placement in air for $1 \mathrm{~h}$, Figure S2: Ea calculations by Ordinary-Integral, MacCallum-Tanner, Satava-Setak methods according to Agrawal method, Table S1: Reactivity parameters obtained from the TG measurements for the surface nitridation calculation. 
Acknowledgments: The authors warmly thank the financial supporting from the Experimental Technology Project (20170209) of Sichuan University, and for the financial support from the open project program of key laboratory of photochemical conversion and optoelectronic materials, TIPC, CAS (PCOM201603).

Author Contributions: Yong Yi and Dai Li designed and performed the nitridation experimental details and the kinetic analysis; Daichuan Ma completed the data calculations of the kinetic triplets; Daibing Luo wrote the main article and provided guidance to the whole experimental process; Weizhong Yang and Wangjing Ma revised the paper and gave suggestions and modifications.

Conflicts of Interest: The authors declare no conflicts of interest.

\section{References}

1. Mench, M.M.; Kuo, K.K.; Yeh, C.L.; Lu, Y.C. Comparison of thermal behavior of regular and ultra-fine aluminum powders (Alex) made from plasma explosion process. Combust. Sci. Technol. 1998, 135, 269-292. [CrossRef]

2. Kwon, Y.S.; Gromov, A.A.; llyin, A.P.; Rim, G.H. Passivation process for superfine aluminum powders obtained by electrical explosion of wires. Appl. Surf. Sci. 2003, 211, 57-67. [CrossRef]

3. Sarathi, R.; Sindhu, T.K.; Chakravathy, S.R. Impact of binary gas on nano-aluminium particle formation through wire explosion process. Mater. Lett. 2007, 61, 1823-1826. [CrossRef]

4. Gromov, A.A.; Förter-Barth, U.; Teipel, U. Aluminum nanopowders produced by electrical explosion of wires and passivated by non-inert coatings: Characterisation and reactivity with air and water. Powder Technol. 2006, 164, 111-115. [CrossRef]

5. Farhat, Z.N.; Ding, Y.; Northwood, D.O.; Alpas, A.T. Effect of grain size on friction and wear of nanocrystalline aluminum. Mater. Sci. Eng. A 1996, 206, 302-313. [CrossRef]

6. Laha, T.; Agarwal, A.; Mckechnie, T.; Rea, K.; Seal, S. Synthesis of bulk nanostructured aluminum alloy component through vacuum plasma spray technique. Acta Mater. 2005, 53, 5429-5438. [CrossRef]

7. Abdoli, H.; Ghanbari, M.; Baghshahi, S. Thermal stability of nanostructured aluminum powder synthesized by high-energy milling. Mater. Sci. Eng. A 2011, 528, 6702-6707. [CrossRef]

8. Zhao, K.Y.; Li, C.J.; Tao, J.M.; Ng, D.H.L.; Zhu, X.K. The synthesis, microstructure, hardness and thermal properties of bulk nanocrystalline $\mathrm{Al}$ produced by in situ consolidation with low-energy ball milling. J. Alloys Compd. 2010, 504, S306-S310. [CrossRef]

9. Cai, B.; Kong, Q.P.; Cui, P.; Cong, H.T.; Sun, X.K. Internal friction of nanocrystalline aluminum prepared by plasma evaporation and compaction. Scr. Mater. 2001, 44, 1043-1048. [CrossRef]

10. Hung, P.C.; Sun, P.L.; Yu, C.Y.; Kao, P.W.; Chang, C.P. Inhomogeneous tensile deformation in ultrafine-grained aluminum. Scr. Mater. 2005, 53, 647-652. [CrossRef]

11. Alihosseini, H.; Zaeem, M.A.; Dehghani, K.; Shivaee, H.A. Producing ultrafine-grained aluminum rods by cyclic forward-backward extrusion: Study the microstructures and mechanical properties. Mater. Lett. 2012, 74, 147-150. [CrossRef]

12. Lei, H.L.; Tang, Y.J.; Li, J.; Luo, J.S.; Li, X.B. In situ organic coating of metal nanoparticles. Appl. Phys. Lett. 2006, 88, 083111. [CrossRef]

13. Foley, T.J.; And, C.E.J.; Higa, K.T. Inhibition of oxide formation on aluminum nanoparticles by transition metal coating. Chem. Mater. 2005, 17, 4086-4091. [CrossRef]

14. Guo, L.; Song, W.; Xie, C.; Zhang, X.; Hu, M. Characterization and thermal properties of carbon-coated aluminum nanoparticles prepared by laser-induction complex heating in methane. Mater. Lett. 2007, 61, 3211-3214. [CrossRef]

15. Tillotson, T.M.; Gash, A.E.; Simpson, R.L.; Hrubesh, L.W.; Satcher, J.H., Jr.; Poco, J.F. Nanostructured energetic materials using sol-gel methodologies. J. Non-Cryst. Solids 2001, 285, 338-345. [CrossRef]

16. Kwon, Y.S.; Gromov, A.A.; Llyin, A.P. Reactivity of superfine aluminum powders stabilized by aluminum diboride. Combust. Flame 2002, 131, 349-352. [CrossRef]

17. Jouet, R.J.; Warrent, A.D.; Rosenberg, D.M.; Bellitto, V.J.; Park, K.-H.; Zachariah, M.R. Surface passivation of bare aluminum nanoparticles using perfluoroalkyl carboxylic acids. Chem. Mater. 2005, 17, 2987-2996. [CrossRef]

18. Mary, B.; Dubois, C.; Carreau, P.J.; Brousseau, P. Rheological properties of suspensions of polyethylene-coated aluminum nanoparticles. Rheol. Acta 2006, 45, 561-573. [CrossRef] 
19. Guo, L.; Song, W.; Hu, M.; Xie, C.; Chen, X. Preparation and reactivity of aluminum nanoparticles coated by hydroxyl-terminated polybutadiene. Appl. Surf. Sci. 2008, 254, 2413-2417. [CrossRef]

20. Lee, S.H.; Yi, J.H.; Kim, J.H.; Ko, Y.N.; Hong, Y.J.; Kang, Y.C. Preparation of nanometer AlN powders by combining spray pyrolysis with carbothermal reduction and nitridation. Ceram. Int. 2011, 37, 1967-1971. [CrossRef]

21. Weimer, A.W.; Cochran, G.A.; Eisman, G.A.; Henley, J.P.; Hook, B.D.; Mills, L.K.; Guiton, T.A.; Knudsen, A.K.; Nichols, N.R.; Volmering, J.E.; et al. Rapid process for manufacturing aluminum nitride powder. J. Am. Ceram. Soc. 1994, 77, 3-8. [CrossRef]

22. Hou, X.; Chou, K.C.; Zhang, X.; Seetharaman, S. Oxidation kinetics of aluminum nitride at different oxidizing atmosphere. J. Alloys Compd. 2008, 465, 90-96. [CrossRef]

23. Hou, X.M.; Yue, C.S.; Singh, A.K.; Zhang, M.; Chou, K.C. Morphological development and oxidation mechanisms of aluminum nitride whiskers. J. Solid State Chem. 2010, 183, 963-968. [CrossRef]

24. Hasani, S.; Panjepour, M.; Shamanian, M. Non-isothermal kinetic analysis of oxidation of pure aluminum powder particles. Oxid. Met. 2014, 81, 299-313. [CrossRef]

25. Fryt, E.M. Application of the Rosenburg kinetic method for determination of the parabolic rate constants for metal oxidation. Oxid. Met. 1978, 12, 139-156. [CrossRef]

26. Linevsky, M.J.; White, D.; Mann, D.E. Infrared spectrum and structure of gaseous $\mathrm{Al}_{2}$ O. J. Chem. Phys. 1964, 41, 542-545. [CrossRef]

27. Vyazovkin, S.V.; Lesnikovich, A.I.; Goryachko, V.I. A method of comparing kinetic curves obtained under isothermal and nonisothermal. Thermochim. Acta 1990, 165, 259-264. [CrossRef]

28. Kissinger, H.E. Reaction kinetics in differential thermal analysis. Anal. Chem. 1957, 29, 1702-1706. [CrossRef]

29. Kuo, K.K.; Deluca, L.T. Combustion of Energetic Materials; Begell House Inc.: New York, NY, USA, 2001.

30. Sossi, A.; Duranti, E.; Paravan, C.; Deluca, L.T.; Vorozhtsov, A.B.; Gromov, A.A.; Pautova, Y.I.; Lerner, M.I.; Rodkevich, N.G. Non-isothermal oxidation of aluminum nanopowder coated by hydrocarbons and fluorohydrocarbons. Appl. Surf. Sci. 2013, 271, 337-343. [CrossRef]

(C) 2018 by the authors. Licensee MDPI, Basel, Switzerland. This article is an open access article distributed under the terms and conditions of the Creative Commons Attribution (CC BY) license (http:/ / creativecommons.org/licenses/by/4.0/). 